\title{
BAFF knockout improves systemic inflammation via regulating adipose tissue distribution in high-fat diet-induced obesity
}

\author{
Do-Hwan Kim and Myoung-Sool Do
}

Obesity is recognized as a chronic low-grade inflammatory state due to adipose tissue expansion being accompanied by an increase in the production of proinflammatory adipokines. Our group is the first to report that B-cell-activating factor (BAFF) is produced from adipocytes and functions as a proinflammatory adipokine. Here, we investigated how loss of BAFF influenced diet-induced obesity in mice by challenging BAFF-I- mice with a high-fat diet for 10 weeks. The results demonstrated that weight gain in BAFF $^{-I-}$ mice was $>30 \%$ than in control mice, with a specific increase in the fat mass of the subcutaneous region rather than the abdominal region. Expression of lipogenic genes was examined by quantitative real-time PCR, and increased lipogenesis was observed in the subcutaneous adipose tissue (SAT), whereas lipogenesis in the epididymal adipose tissue (EAT) was reduced. A significant decrease in EAT mass resulted in the downregulation of inflammatory gene expression in EAT, and more importantly, overall levels of inflammatory cytokines in the circulation were reduced in obese BAFF $-1-$ mice. $^{-}$ We also observed that the macrophages recruited in the enlarged SAT were predominantly M2 macrophages. 3T3-L1 adipocytes were cultured with adipose tissue conditioned media (ATCM), demonstrating that EAT ATCM from BAFF-l- mice contains antilipogenic and anti-inflammatory properties. Taken together, BAFF ${ }^{-1-}$ improved systemic inflammation by redistributing adipose tissue into subcutaneous regions. Understanding the mechanisms by which BAFF regulates obesity in a tissue-specific manner would provide therapeutic opportunities to target obesity-related chronic diseases.

Experimental \& Molecular Medicine (2015) 47, e129; doi:10.1038/emm.2014.98; published online 16 January 2015

\section{INTRODUCTION}

Obesity has been shown to be closely associated with the increased morbidity and mortality associated with metabolic syndrome, which includes type 2 diabetes, atherosclerosis, hypertension, stroke and cancers. ${ }^{1-3}$ In the setting of a chronic positive energy balance, adipose tissue expands to accommodate excess energy. This leads to an increase in the secretion of proinflammatory cytokines such as tumor necrosis factor- $\alpha$ (TNF $\alpha)$ and monocyte chemotactic protein-1 (MCP-1). ${ }^{4-6}$ Furthermore, the adipocyte-secreted molecules such as leptin, resistin and adiponectin, collectively termed adipokines, also function as inflammatory molecules in obesity. ${ }^{7-9}$ In addition, a large number of proinflammatory cytokines produced by adipocytes have been introduced as novel adipokines, ${ }^{10-13}$ which further strengthens the ideology that adipose tissue acts as a major endocrine organ that drives systemic chronic inflammation and obesity-related metabolic diseases.
B-cell-activating factor (BAFF, also known as BLyS and TNFSF13B) is a member of the TNF ligand superfamily. It is mainly expressed in B-cell lineage cells and has a role in B-cell proliferation and differentiation. ${ }^{14-16}$ There are three types of receptors for BAFF: BAFF receptor (BAFF-R), B-cell maturation antigen and transmembrane activator and calcium signalmodulating cytophilic ligand. BAFF is expressed on the plasma membrane as a trimer via TNF homology domain-15 and is secreted after being cleaved by furin-like protease. ${ }^{17}$ The BAFF trimer binds BAFF-R, which is expressed on the plasma membrane in a trimeric form. ${ }^{18}$ Secreted BAFF can form a 60 -mer by assembly of 20 units of trimers through an unusually long D-E loop, ${ }^{18}$ which preferentially binds to transmembrane activator and calcium signal-modulating cytophilic ligand. BAFF- $\mathrm{R}$ is expressed on the plasma membrane of mature adipocytes, whereas B-cell maturation antigen or transmembrane activator and calcium signal-modulating cytophilic ligand have limited expression. ${ }^{19}$ Instead, B-cell

School of Life Science, Handong Global University, Pohang, Gyungbuk, Korea

Correspondence: Professor M-S Do, School of Life Science, Handong Global University, 3 Namsong-ri, Heunghae-eup, Buk-gu, Pohang, Gyungbuk 791-708, Korea. 
maturation antigen is localized to the Golgi apparatus, ${ }^{20}$ and evidence suggests that BAFF weakly binds B-cell maturation antigen. ${ }^{21}$

Our group was the first to report that BAFF is produced by adipocytes. ${ }^{22}$ Using the widely used and well-characterized human preadipocyte cell strain, Simpson-Golabi-Behmel syndrome $^{23,24}$ and mouse 3T3-L1 cells, we identified that levels of BAFF expression change under pro- and anti-inflammatory conditions, suggesting that BAFF is a novel adipokine that links inflammation to obesity. ${ }^{12,22}$ Using mouse models, we have demonstrated that BAFF expression levels in adipose tissue were positively correlated with genetic and diet-induced obesity. ${ }^{12,25}$ Furthermore, we have found that BAFF triggers the expression of adipokines and that the interaction between adipocytes and macrophages augments the level of BAFF expression and secretion. ${ }^{25}$ Given that macrophage infiltration in adipose tissue is one of the pathological processes in obesityassociated metabolic syndrome, ${ }^{26}$ it is logical to conclude that BAFF mediates metabolic syndrome in obesity as an autocrine and/or paracrine factor.

Involvement of BAFF in autoimmunity has been suggested in BAFF transgenic mice. ${ }^{27}$ Overexpression of BAFF induced phenotypes of autoimmune diseases such as an increased number of immune cells, autoantibodies and circulating immune factors. Recently, BAFF-R was considered as a potential therapeutic target for the cure of atherosclerosis when the development of atherosclerosis was prevented in BAFF-Rdeficient mice ${ }^{28}$ or by BAFF-R antibody treatment. ${ }^{29}$ Interestingly, the involvement of BAFF in obesity-related metabolic dysregulation such as insulin resistance ${ }^{30}$ and oxidative stress ${ }^{31}$ has been demonstrated. Hamada et al. ${ }^{30}$ reported that BAFF inhibits insulin-stimulated glucose uptake and insulin signaling in vitro. They also demonstrated that oxidative stress is a factor that increases BAFF expression in obesity. ${ }^{30}$ In contrast, the protective role of BAFF in hepatic steatosis was suggested, as BAFF-R knockout mice developed hepatic steatosis when fed with a high-fat diet (HFD), ${ }^{32}$ yet the HFD-induced obesity was shown to be mitigated in those mice. Taken together, it is clear that BAFF unites obesity with metabolic syndrome. However, there is a lack of understanding regarding the mechanistic effect of BAFF in the development of systemic inflammation in obesity.

In this report, we aimed to identify a role for BAFF in obesity-induced systemic inflammation. We induced obesity in $\mathrm{BAFF}^{-/-}$mice via an HFD and examined changes in lipogenesis and inflammation in the presence or absence of BAFF. Our findings suggest that BAFF regulates systemic inflammation via redistribution of lipid accumulation in obesity.

\section{MATERIALS AND METHODS}

\section{Diet-induced obesity in mice}

Six-week-old C57BL/6 mice were purchased from Central Lab Animal Inc. (Seoul, Korea), and BAFF knockout mice were purchased from The Jackson Laboratory (Bar Harbor, ME, USA; stock number 010572). Systemic BAFF knockout mice were generated by insertion of the tailless human CD2 reporter gene into the BAFF locus. Mice were fed with a standard chow diet for a week to allow acclimation. The mice were separated into two groups and were fed either a standard chow or HFD containing $60 \%$ fat for 10 weeks. All mice were housed in cages on a 12-h light/dark cycle at a temperature of $22 \pm 1{ }^{\circ} \mathrm{C}$ and humidity of $55 \pm 5 \%$. Food intake was measured weekly.

\section{T3-L1 adipocyte culture}

3T3-L1 preadipocytes purchased from the American Type Culture Collection (Manassas, VA, USA) were cultured in Dulbecco's modified Eagles' medium (DMEM) (Hyclone, Logan, UT, USA) containing $10 \%$ bovine calf serum (Hyclone) at $37^{\circ} \mathrm{C}$ in a humidified atmosphere of $5 \% \mathrm{CO}_{2}$. After 2 or 3 days, cells were subcultured into $35-\mathrm{mm}$ plates at a concentration of $3 \times 10^{4}$ cells per plate. At 2 days postconfluence (designated as day 0 ), cell differentiation was induced with a mixture of IBMX (methylisobutylxanthine, $50 \mathrm{~mm}$; SigmaAldrich, St Louis, MO, USA), dexamethasone (1 mM; Sigma-Aldrich) and insulin $\left(1 \mathrm{mg} \mathrm{ml}^{-1}\right.$; Sigma-Aldrich) in DMEM containing $10 \%$ fetal bovine serum (Hyclone). At days 2 and 4, the medium was replaced with DMEM containing $10 \%$ fetal bovine serum and insulin $\left(1 \mathrm{mg} \mathrm{ml}^{-1}\right)$. At day 6 , the medium was replaced with DMEM containing $10 \%$ fetal bovine serum only. At day 8 , cells were treated with recombinant BAFF $\left(10 \mathrm{ng} \mathrm{ml}^{-1}\right)$ and BAFF-R antibody (200 $\mathrm{ng} \mathrm{ml}^{-1}$ ) (R\&D Systems, Minneapolis, MN, USA) for $24 \mathrm{~h}$. Cells and the conditioned medium were collected for RNA extraction and enzyme-linked immunosorbent assay, respectively.

\section{Adipose tissue conditioned medium}

Subcutaneous adipose tissue (SAT) and epididymal adipose tissue (EAT) were obtained from control and $\mathrm{BAFF}^{-1-}$ mice. Mice were fed with an HFD (60\% fat) for 10 weeks. Adipose tissue was immediately cut into small pieces in ice-cold phosphate-buffered saline and washed with washing buffer $\left(0.15 \mathrm{M} \mathrm{NaCl}, 10 \mathrm{mM} \mathrm{KH}_{2} \mathrm{PO}_{4}, 5 \mathrm{~mm}\right.$ glucose, penicillin, gentamycin and amphotericin $\mathrm{B})$. The resulting tissue fragments were transferred to 6-well tissue culture plates $(100 \mathrm{mg}$ per well). Conditioned medium was generated by incubating the explants in DMEM supplemented with $0.2 \%$ amphotericin B in an atmosphere of $5 \% \mathrm{CO}_{2}$ at $37^{\circ} \mathrm{C}$. The explants were cultured for $72 \mathrm{~h}$, and the conditioned medium was then filter-sterilized and stored at $-80^{\circ} \mathrm{C}$ until use. $3 \mathrm{~T} 3$ - $\mathrm{L} 1$ adipocytes, 8 days after differentiation, were treated with $1 \mathrm{ml}$ per well adipose tissue conditioned media (ATCM) for $24 \mathrm{~h}$. As a control, cells were cultured in the same condition but with DMEM only. Cells were collected for RNA extraction.

\section{RNA extraction and cDNA synthesis}

Total RNA was isolated from 3T3-L1 adipocytes using QIAzol reagent (Qiagen, Hilden, Germany). cDNA synthesis was performed with $1 \mu \mathrm{g}$ of total RNA using ImProm-II reverse transcriptase (Promega, Madison, WI, USA). Reactions were incubated at $24^{\circ} \mathrm{C}$ for $5 \mathrm{~min}$, $42^{\circ} \mathrm{C}$ for $60 \mathrm{~min}$ and $70{ }^{\circ} \mathrm{C}$ for $15 \mathrm{~min}$. Synthesized cDNA was diluted with $80 \mu \mathrm{l}$ double distilled water.

\section{Real-time PCR}

Real-time PCR analysis was performed using the Applied Biosystems 7500 Real-Time PCR System (Applied Biosystems, Foster City, CA, USA). The CDNA, appropriate primers, ROX dye and HotStart-IT SYBR Green qPCR Master Mix (USB Corporation, Cleveland, $\mathrm{OH}$, USA) were incubated at $94^{\circ} \mathrm{C}$ for $2 \mathrm{~min}$, then for 45 cycles of $95^{\circ} \mathrm{C}$ for $15 \mathrm{~s}$ and finally $60^{\circ} \mathrm{C}$ for $1 \mathrm{~min}$. Oligonucleotide primer sequences used are listed in Table 1. 
Table 1 Gene-specific primers used for RT-PCR

\begin{tabular}{|c|c|c|c|}
\hline Gene name & Accession no. & & Sequence \\
\hline \multirow[t]{2}{*}{$\beta$-actin } & NM_007393 & Forward & 5'-AGCCATGTACGTAGCCATCC-3' \\
\hline & & Reverse & 5'-TCССTCTCAGCTGTGGTGGTGAA-3' \\
\hline FAS & & Reverse & 5'-CATTTCCTGAAGTTTCCGCAG-3' \\
\hline \multirow[t]{2}{*}{$A C C$} & NM_133360 & Forward & 5'-TGACAGACTGATCGCAGAGAAAG-3' \\
\hline & & Reverse & 5'-TGGAGAGCCCCACACACA-3' \\
\hline CPT-1 & & Reverse & 5'-ATGGAACTGGTGGCCAATGA-3' \\
\hline \multirow[t]{2}{*}{ Adiponectin } & NM_017370 & Forward & 5'-GTCTCAGCTGTCCTTCCCCT-3' \\
\hline & & Reverse & 5'-CCCTGGCTTTATGCTCTTTGGC-3' \\
\hline \multirow[t]{2}{*}{ Perilipin } & NM_175640 & Forward & 5'-AGATCCCGGCTCTTCAATACC-3' \\
\hline & & Reverse & 5'-AGAACCTTGTCAGAGGTGCTT-3' \\
\hline PPAR & NM_005037 & Forward & 5'-AGTGGAGACCGCCCAGG-3' \\
\hline \multirow[t]{2}{*}{ ACS } & NM_007981 & Forward & 5'-TGACCTCCTCATGCAGTCAG-3' \\
\hline & & Reverse & 5'-GAGCCTATGCACTCAGCCCAGT-3' \\
\hline \multirow[t]{2}{*}{$D G A T$} & NM_010046 & Forward & 5'-AGCTGGCGGTCCCCAACCAT-3' \\
\hline & & Reverse & 5'-GCACCACCTGTGCACGGGGA-3' \\
\hline \multirow[t]{2}{*}{$L P L$} & NM_008509 & Forward & 5'-GGGAGTTTGGCTCCAGAGTTT-3' \\
\hline & & Reverse & 5'-TGTGTCTTCAGGGGTCCTTAG-3' \\
\hline \multirow[t]{2}{*}{ SREBP1C } & NM_011480 & Forward & 5'-AGCAGCCCCTAGAACAAACAC-3' \\
\hline & & Reverse & 5'-CAGCAGTGAGTCTGCCTTGAT-3' \\
\hline \multirow[t]{2}{*}{ Leptin } & NM_008493 & Forward & 5'-TGACACCAAAACCCTCATCA-3' \\
\hline & & Reverse & 5'-TCATTGGCTATCTGCAGCAC-3' \\
\hline$M C P-1$ & NM_011333 & Forward & 5'-CGGAACCAAATGAGATCAGAA-3' \\
\hline \multirow[t]{2}{*}{ IFNy } & NM_008337 & Forward & 5'-ATGAACGCTACACACTGCATC-3' \\
\hline & & Reverse & 5'-CCATCCTTTTTGCCAGTTCCTC-3' \\
\hline \multirow[t]{2}{*}{$T N F \alpha$} & TNM_013693 & Forward & 5'-ACTGCCAGAAGAGGCACTCC-3' \\
\hline & & Reverse & 5'-CGATCACCCCGAAGTTCA-3' \\
\hline \multirow[t]{2}{*}{$F 4 / 80$} & NM_010130 & Forward & 5'-AGTACGATGTGGGGCTTTTG-3' \\
\hline & & Reverse & 5'-ССССАTСTGTACATCССАСТ-3' \\
\hline \multirow[t]{2}{*}{$C D 11 b$} & NM_008401 & Forward & 5'-CCCCACACTAGCATCAAGGG-3' \\
\hline & & Reverse & 5'-GAGGCAAGGGACACACTGAC-3' \\
\hline \multirow[t]{2}{*}{ CD86 } & NM_019388 & Forward & 5'-TCTGCCGTGCCCATTTACAA-3' \\
\hline & & Reverse & 5'-TGTGCCCAAATAGTGCTCGT-3' \\
\hline CD163 & NM_053094 & Forward & 5'-GACTTGCTGAAATCCTCGGAAAA-3' \\
\hline & & Reverse & 5'-AGTGTGCCTCTGAATGACCC-3' \\
\hline $\operatorname{Arg} I$ & NM_009705 & Forward & 5'-TCTCСTCCACGGGCAAATTC-3' \\
\hline & & Reverse & 5'-GCAAGCCAGCTTCTCGAATG-3' \\
\hline Clec10a & NM_010796 & Forward & 5'-CTCTGGAGAGCACAGTGGAG-3' \\
\hline & & Reverse & 5'-ACTTCCGAGCCGTTGTTCT-3' \\
\hline
\end{tabular}

Abbreviations: ACC, acetyl-CoA carboxylase; ACS, acetyl-CoA synthetase; Arg I, arginase-1; Clec10a, C-type lectin domain family 10, member A; COX-2, prostaglandin-endoperoxide synthase 2; CPT-1, carnitine palmitoyl acyltransferase- 1 ; DGAT, diglyceride acyltransferase; FAS, fatty acid synthase; IFN $\gamma$, interferon- $\gamma$; IL-6, interleukin-6; LPL, lipoprotein lipase; MCP-1, monocyte chemotactic protein-1; PGC1 $\alpha$, PPAR $\gamma$ coactivator $1 \alpha$; PPAR $\gamma$, peroxisome proliferator-activated receptor $\gamma$; SREBP1c, sterol regulatory element binding protein $1 c$; TNF $\alpha$, tumor necrosis factor- $\alpha$. 


\section{Enzyme-linked immunosorbent assay}

The mouse MCP-1/INF- $\gamma$ enzyme-linked immunosorbent assay set was purchased from BD Bioscience (Heidelberg, Germany). Mouse leptin capture antibody and biotinylated antibody were purchased from R\&D Systems. All experiments were performed according to the manufacturer's instructions.

\section{Hematoxylin and eosin staining}

For visualization of adipocytes in subcutaneous adipose tissue and epididymal adipose tissue, each tissue was fixed in $3.8 \%$ formaldehyde. Adipose tissues were sectioned and stained with hematoxylin and eosin. The size and number of adipocytes were measured.

\section{Oil Red O staining}

Cultured adipocytes were fixed with $10 \%$ fresh formalin (Sigma, St Louis, MO, USA) and rinsed with phosphate-buffered saline. Cells were incubated in filtered Oil Red $\mathrm{O}$ staining solution (Sigma) at $4{ }^{\circ} \mathrm{C}$ for $1 \mathrm{~h}$. After the staining solution was removed, the dye retained in the cells was eluted with isopropanol and the optical density at $540 \mathrm{~nm}$ was determined.

\section{Statistical analysis}

The data were analyzed by Student's $t$-test. A $P$-value of $<0.05$ was considered to be significant.

\section{RESULTS}

HFD increased fat mass of SAT but not EAT in

BAFF $^{-1-}$ mice

Obesity was induced in control and $\mathrm{BAFF}^{-/-}$mice by feeding with an HFD for 10 weeks. $\mathrm{BAFF}^{-/-}$mice responded to HFD feeding with an accelerated body weight gain compared with control mice (Figure 1a). Statistical analysis of weight gain revealed a significant difference between $\mathrm{BAFF}^{-1-}$ and control mice from 6 weeks of HFD feeding onward (week 6, $P<0.05$; week $7, P<0.01$; week $8-10, P<0.001)$. It is noteworthy that the initial body weight of $\mathrm{BAFF}^{-1-}$ mice was lower than that of control mice, so the percentage of total weight gain was significantly higher in $\mathrm{BAFF}^{-/-}$mice compared with control mice (Figure 1b). The amount of food intake was not significantly different between the two groups of mice (Figure 1c). Evaluation of body composition between control and $\mathrm{BAFF}^{-1-}$ mice revealed that there was an increase in fat mass in the SAT, whereas there was a decrease in the fat mass of the EAT relative to control mice when normalized to body weight (Figure 1d).

Lipogenesis was altered in the presence or absence of BAFF To evaluate mechanisms leading to the increased adiposity in $\mathrm{BAFF}^{-1-}$ mice, we measured the expression of genes associated with lipogenesis and lipolysis. The mRNA expression of enzymes involved in lipogenesis, fatty acid synthase (FAS), acetyl-CoA carboxylase and perilipin was examined and
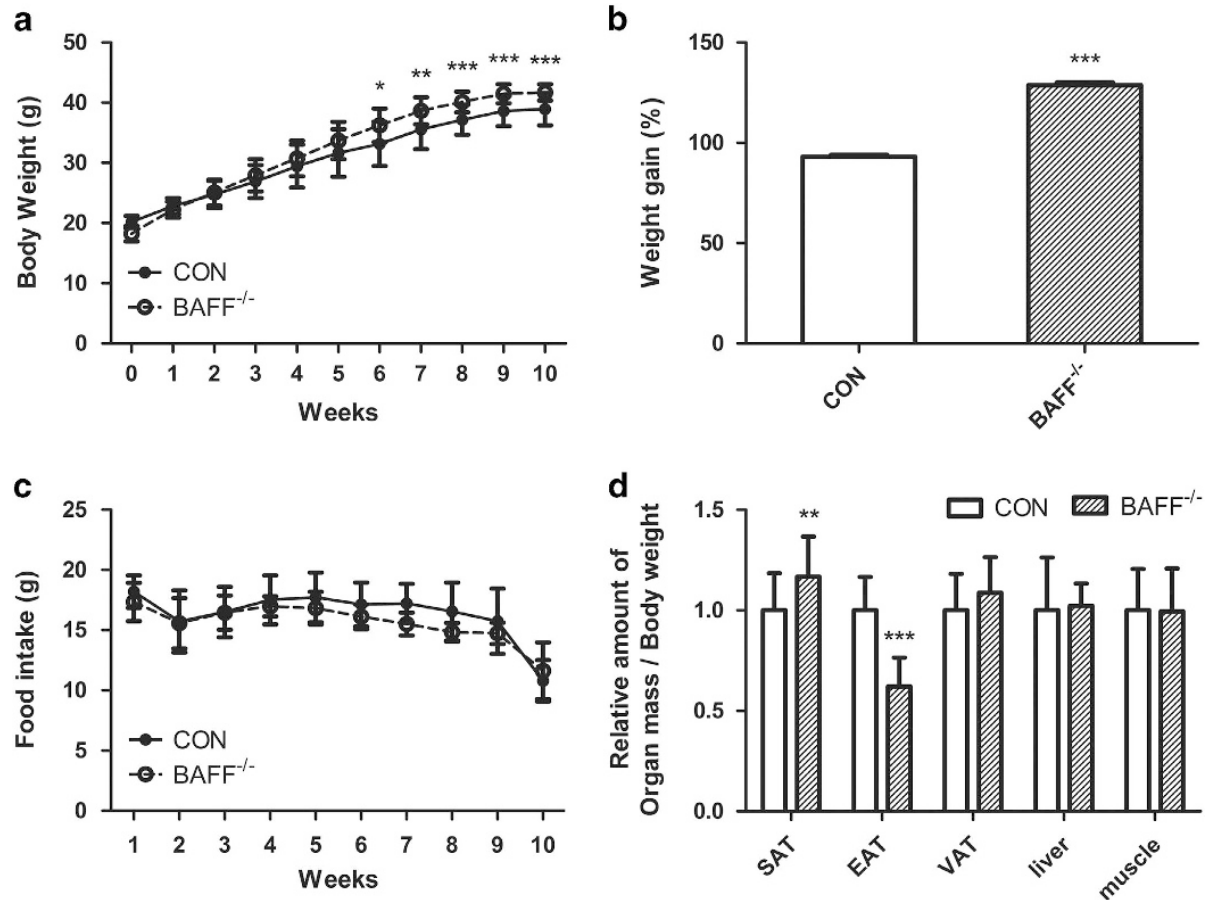

Figure 1 Animal model. Seven-week-old male C57BL/6J mice ( $n=21$ per group) were fed a high-fat diet (HFD) (60\% fat) for 10 weeks to induce obesity. Body weight and food consumption were monitored once per week. (a) Body weight gain in control/BAFF ${ }^{-1-}$ mice showed a significant difference. (b) Relative weight gain in control/BAFF-/- mice after 10 weeks of HFD feeding expressed as a percent change from initial weight. (c) Food intake in grams. (d) Relative organ weight in grams: (organ weight/body weight) $\times 100 \%$. Mean values with letters are significantly different $\left({ }^{*} P<0.05,{ }^{*} P<0.01\right.$ and $\left.{ }^{* * *} P<0.001\right)$ by Student's $t$-test. BAFF, B-cell-activating factor; CON, control; EAT, epididymal adipose tissue; SAT, subcutaneous adipose tissue; VAT, visceral adipose tissue. 

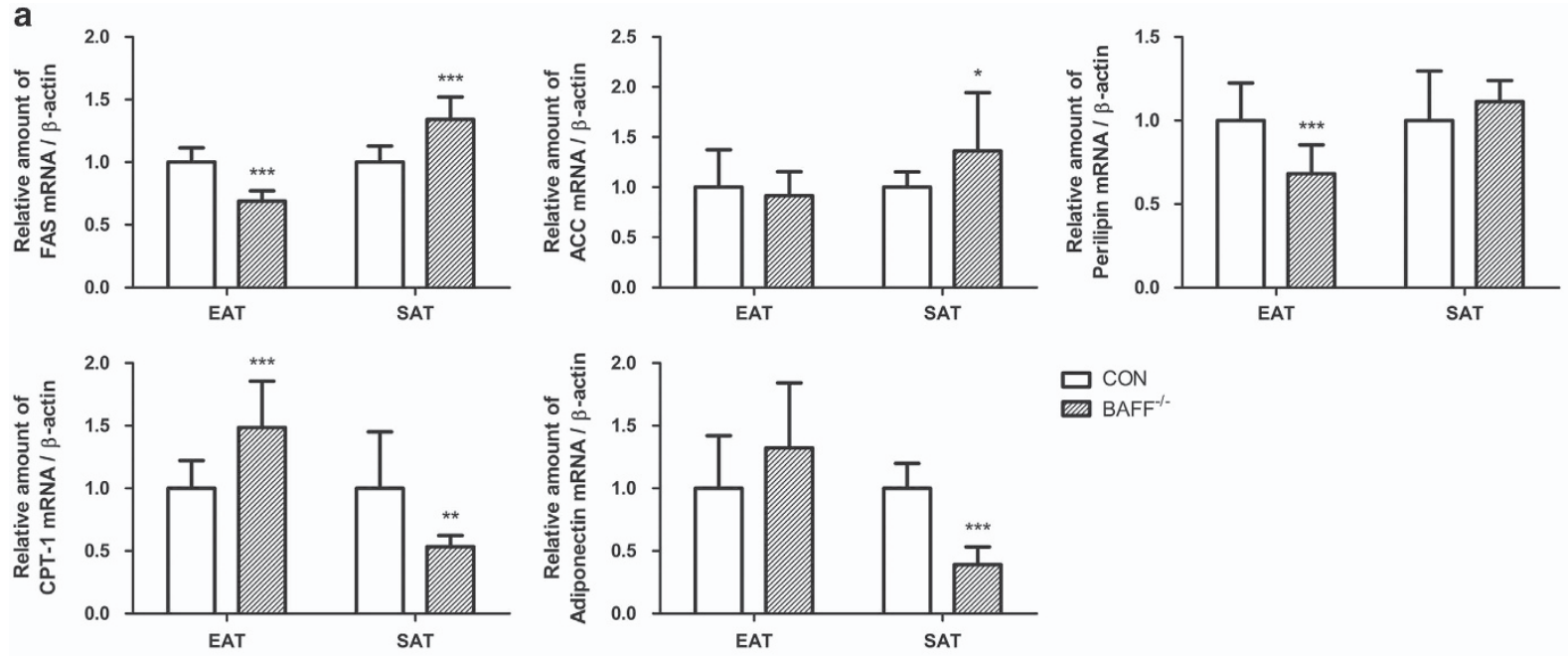

b

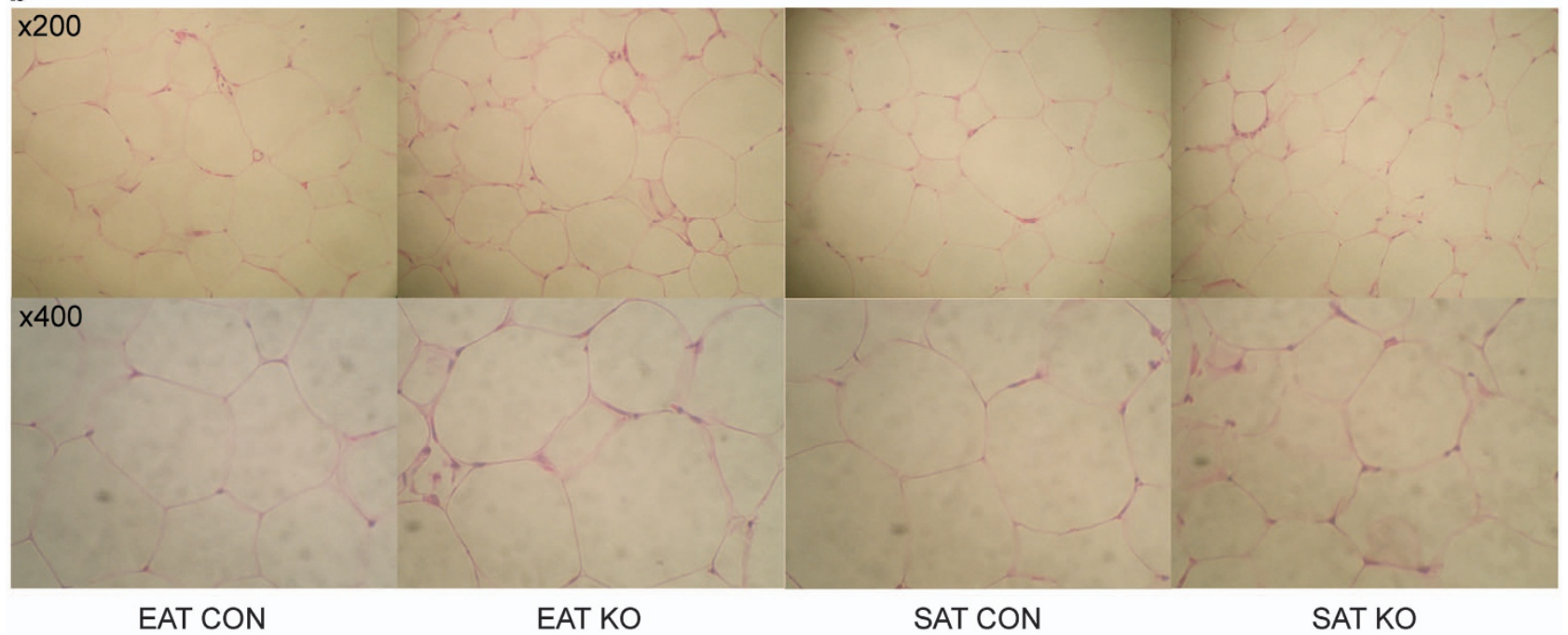

Figure 2 Change in lipogenic enzymes in fat tissue. (a) Analysis of fatty acid synthase (FAS), acetyl-CoA carboxylase (ACC), perilipin, carnitine palmitoyl acyltransferase-1 (CPT-1) and adiponectin mRNA expression in epididymal adipose tissue (EAT) and subcutaneous adipose tissue (SAT) from high-fat diet (HFD)-induced obese mice. The data are presented as $x$-fold expression of control mice ( $n=21$ mice per group; genes were analyzed separately). Black columns and symbols represent BAFF-1- mice; white: control. (b) WAT morphology was determined by hematoxylin and eosin (H\&E) staining of slides of paraffin-embedded EAT and SAT $(\times 200, \times 400 \times)$. (c) At day 8 after inducing differentiation, adipocytes were cultured in a $35-\mathrm{mm}$ dish with $10 \mathrm{ng} \mathrm{ml^{-1 }}$ BAFF and the addition of $200 \mathrm{ng} \mathrm{ml}^{-1}$ BAFF-R antibody $(n=8)$. As a control, cells were cultured in the same condition but without BAFF and BAFF-R antibody treatment. The graph represents mRNA expression of peroxisome proliferator-activated receptor $\gamma$ (PPAR $\gamma$ ), PPAR $\gamma$ coactivator $1 \alpha$ (PGC1 $\alpha$ ), acetyl-CoA synthetase (ACS), diglyceride acyltransferase (DGAT), lipoprotein lipase (LPL), sterol regulatory element binding protein 1c (SREBP1c), perilipin and leptin. mRNA analysis results are expressed relative to untreated control cells and represented as the mean \pm s.e. Experiments were conducted two times. Mean values with letters are significantly different $\left({ }^{*} P<0.05,{ }^{* *} P<0.01\right.$ and $\left.* * * P<0.001\right)$ by Student's $t$-test. (d) Adipocyte morphology was determined by Oil Red 0 staining $(\times 400)$. Ab, antibody; BAFF, B-cell-activating factor; BAFF-R, BAFF receptor; CON, control; KO, knockout.

found to be decreased in the EAT but increased in the SAT. Conversely, the expression of carnitine palmitoyl acyltransferase- 1 and adiponectin were reduced in SAT but induced in EAT (Figure 2a), suggesting increased lipogenesis and decreased lipolysis in SAT of $\mathrm{BAFF}^{-1-}$ mice. Hematoxylin and eosin staining showed that SAT of $\mathrm{BAFF}^{-1-}$ mice produced a greater number of adipocytes that were of a smaller size compared with EAT adipocytes. However, there was no significant change in the morphology of EAT (Figure 2b).

To determine whether lipogenic enzyme expression is regulated by BAFF, we examined the expression of peroxisome proliferator-activated receptor $\gamma(\operatorname{PPAR} \gamma), \operatorname{PPAR} \gamma$ coactivator $1 \alpha(\mathrm{PGC} 1 \alpha)$, acetyl-CoA synthetase, diglyceride acyltransferase, lipoprotein lipase (LPL), sterol regulatory element binding protein 1c (SREBP1c), perilipin and leptin 
c
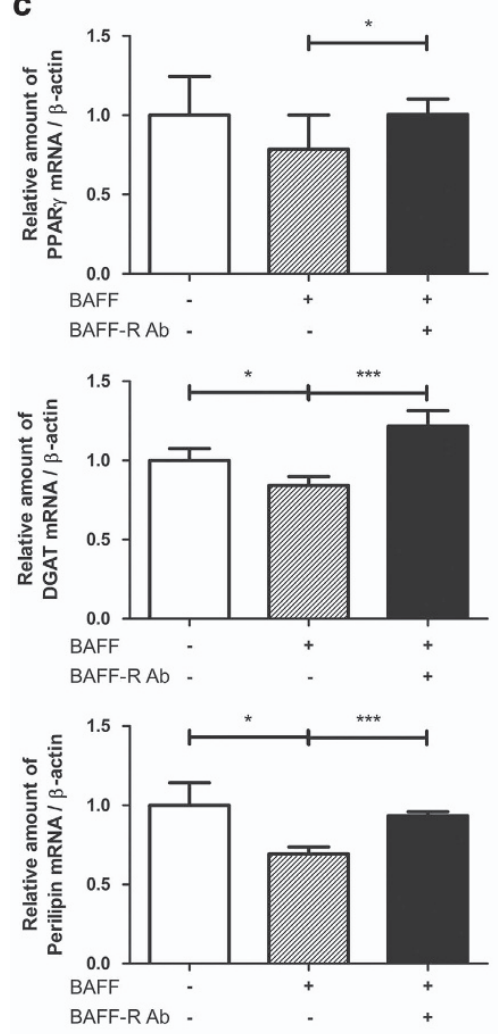

d

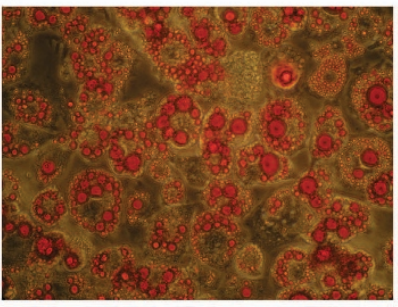

BAFF BAFF-R Ab
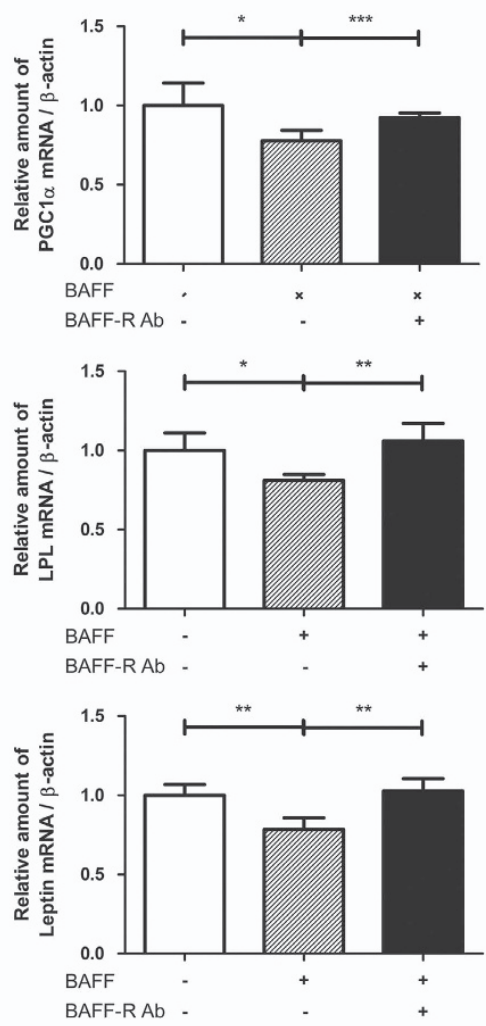
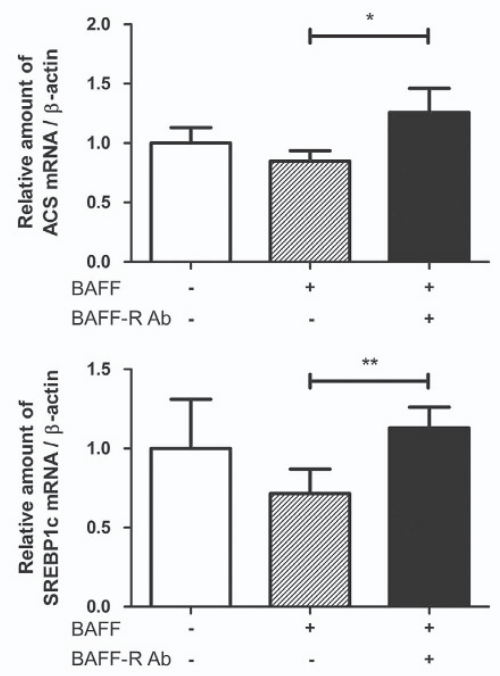

Figure 2 Continued.

in BAFF-treated 3T3-L1 adipocytes. The mRNA expression of all genes was downregulated by BAFF treatment and then reversed by the blockage of BAFF signaling with the addition of the neutralizing BAFF-R antibody (Figure 2c). As shown in Figure 2d, Oil Red $\mathrm{O}$ staining indicated that BAFF treatment reduced lipid accumulation in 3T3-L1 adipocytes. Quantitatively, an $\sim 8 \%$ reduction in lipid accumulation was measured in BAFF-treated cells compared with controls; this reduction was inhibited by BAFF-R antibody treatment (Figure 2d).

Reduced systemic inflammation in HFD-fed $\mathrm{BAFF}^{-1-}$ mice In previous studies, we showed that the mRNA expression of proinflammatory adipokines significantly increased in BAFF-treated 3T3-L1 adipocytes. ${ }^{25}$ From this finding, we hypothesized that BAFF mediates inflammation in obesity. To examine this hypothesis, we first measured the expression of genes associated with inflammation in adipose tissue from HFD-fed control and $\mathrm{BAFF}^{-1-}$ mice. The mRNA expression of these molecules was all decreased in EAT of $\mathrm{BAFF}^{-/-}$mice compared with control mice. In the SAT, they were either unchanged (MCP-1, haptoglobin and leptin) or increased (interleukin-6 (IL-6) and prostaglandin-endoperoxide synthase $2(\mathrm{COX}-2)$ ) in $\mathrm{BAFF}^{-1-}$ mice (Figure 3a). To determine whether these changes in mRNA expression were related to systemic inflammation, we measured leptin, MCP-1 and IFN $\gamma$ levels in the serum. As expected, significantly lower levels of inflammatory markers were detected from $\mathrm{BAFF}^{-1-}$ mice serum compared with controls (Figure 3b). As a complementary method, we treated BAFF in 3T3-L1 adipocytes and examined the expression of TNF $\alpha$ and IL-6. TNF $\alpha$ and IL-6 expression levels increased with BAFF treatment and recovered with additional BAFF-R antibody (Figure 3c). 

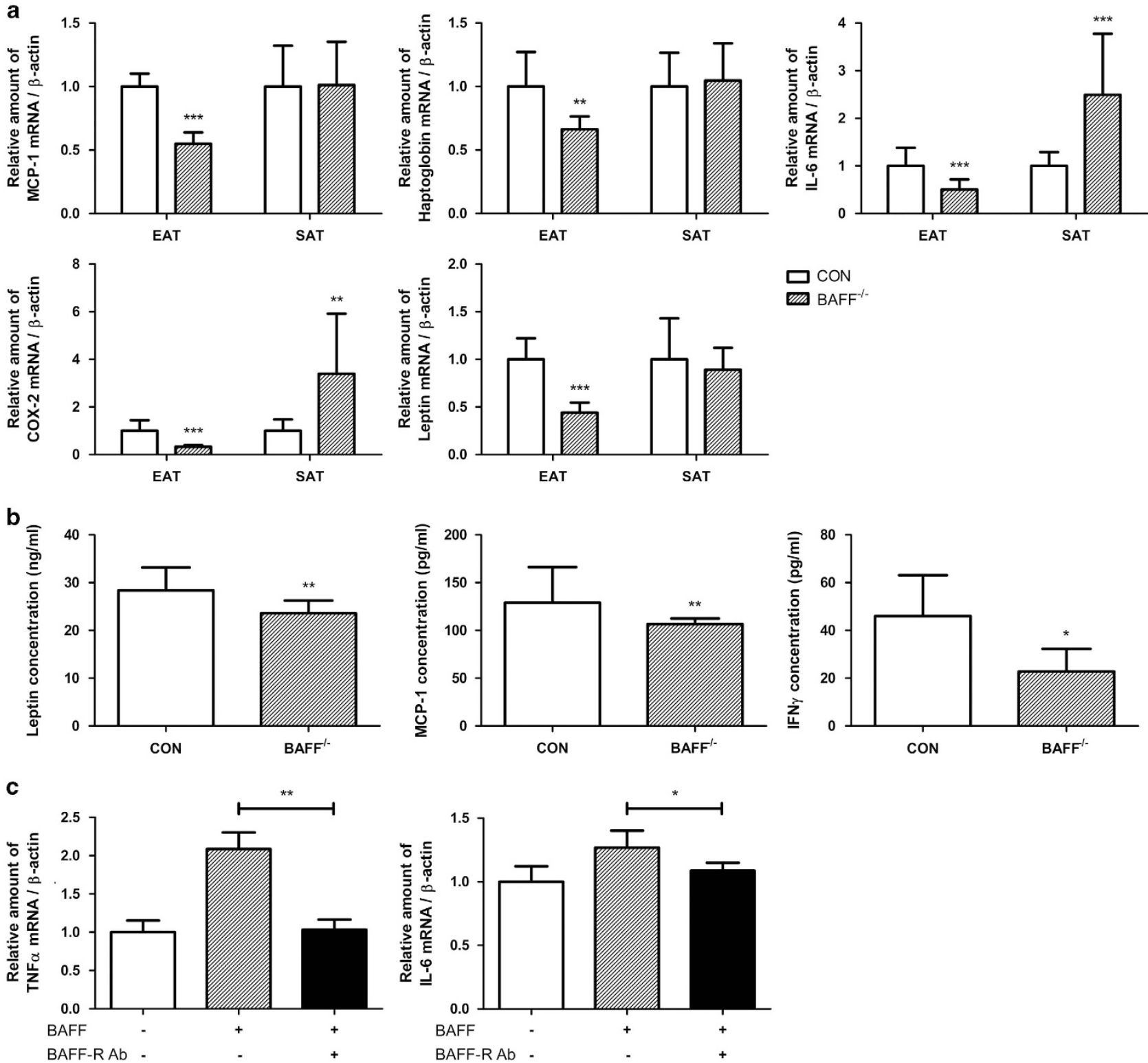

Figure 3 Change in inflammatory enzymes in fat tissue. (a) Analysis of monocyte chemotactic protein-1 (MCP-1), haptoglobin, interleukin-6 (IL-6), prostaglandin-endoperoxide synthase 2 (COX-2) and leptin mRNA expression in epididymal adipose tissue (EAT) and subcutaneous adipose tissue (SAT) from high-fat diet (HFD)-induced obese mice. (b) Enzyme-linked immunosorbent assay (ELISA) of leptin, MCP-1 and interferon- $\gamma$ (IFN $\gamma$ ) in the serum from HFD-induced obese mice. The data are presented as $x$-fold expression of control mice ( $n=21$ mice per group; genes were analyzed separately). Black columns and symbols represent BAFF-1- mice; white: control. (c) At day 8 after inducing differentiation, adipocytes were cultured in a 35-mm dish with $10 \mathrm{ng} \mathrm{ml}^{-1}$ BAFF and the addition of $200 \mathrm{ng} \mathrm{ml}^{-1}$ BAFF-R antibody $(n=8)$. As a control, cells were cultured in the same condition but without BAFF and BAFF-R antibody treatment. The graph represents mRNA expression of tumor necrosis factor- $\alpha$ (TNF $\alpha$ ), IL- 6 and adiponectin. mRNA analysis results are expressed relative to untreated control cells and are represented as the mean \pm s.e. Experiments were conducted two times. Mean values with letters are significantly different $\left({ }^{*} P<0.05,{ }^{*} P<0.01\right.$ and $\left.{ }^{* * *} P<0.001\right)$ by Student's $t$-test. Ab, antibody; BAFF, B-cell-activating factor; BAFF-R, BAFF receptor; CON, control.

The culture of 3T3-L1 adipocytes with ATCM confirms in vivo data

To confirm the mRNA expression changes observed in the $\mathrm{BAFF}^{-1-}$ mouse model, 3T3-L1 adipocytes were treated with conditioned media (ATCM) from $\mathrm{BAFF}^{-/-}$and control mice. As expected, there was no BAFF in ATCM from
$\mathrm{BAFF}^{-1-} \mathrm{SAT}$ and EAT, whereas BAFF was present in ATCM from control mice (data not shown). Consistent with the in vivo results, when cells were treated with ATCM from $\mathrm{BAFF}^{-1-} \mathrm{EAT}$, the expression of lipogenic enzymes (FAS, PGC1 $\alpha$, acetyl-CoA synthetase, SREBP1c, diglyceride acyltransferase, LPL and HSL) decreased significantly. 

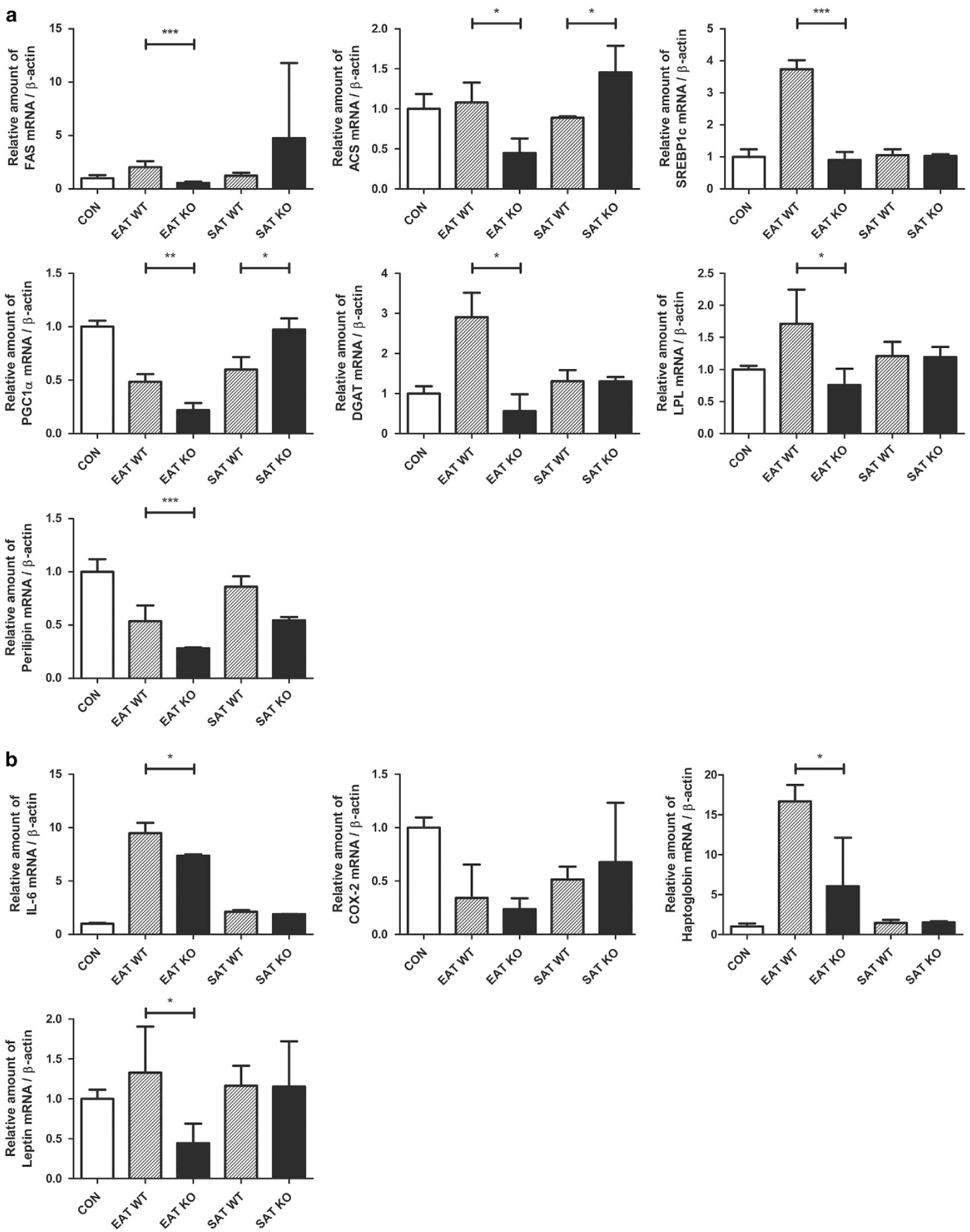

Figure 4 3T3-L1 cells treated with adipose tissue-conditioned media (ATCM). (a) At day 8 after inducing differentiation, adipocytes were cultured in a 35-mm dish with ATCM $(n=8)$. As a control, cells were cultured with wild-type (WT) ATCM treatment. The graph represents mRNA expression of fatty acid synthase (FAS), acetyl-CoA synthetase (ACS), sterol regulatory element binding protein 1c (SREBP1c), PPAR $\gamma$ coactivator $1 \alpha(P G C 1 \alpha)$, diglyceride acyltransferase (DGAT), lipoprotein lipase (LPL) and perilipin. (b) The graph represents mRNA expression of interleukin-6 (IL-6), prostaglandin-endoperoxide synthase 2 (COX-2), haptoglobin and leptin. mRNA analysis results are expressed relative to untreated control cells and represented as the mean \pm s.e. Experiments were conducted two times. Mean values with letters are significantly different $\left({ }^{*} P<0.05,{ }^{*} P<0.01\right.$ and $\left.{ }^{* * *} P<0.001\right)$ by Student's $t$-test. CON, control; KO, knockout. 

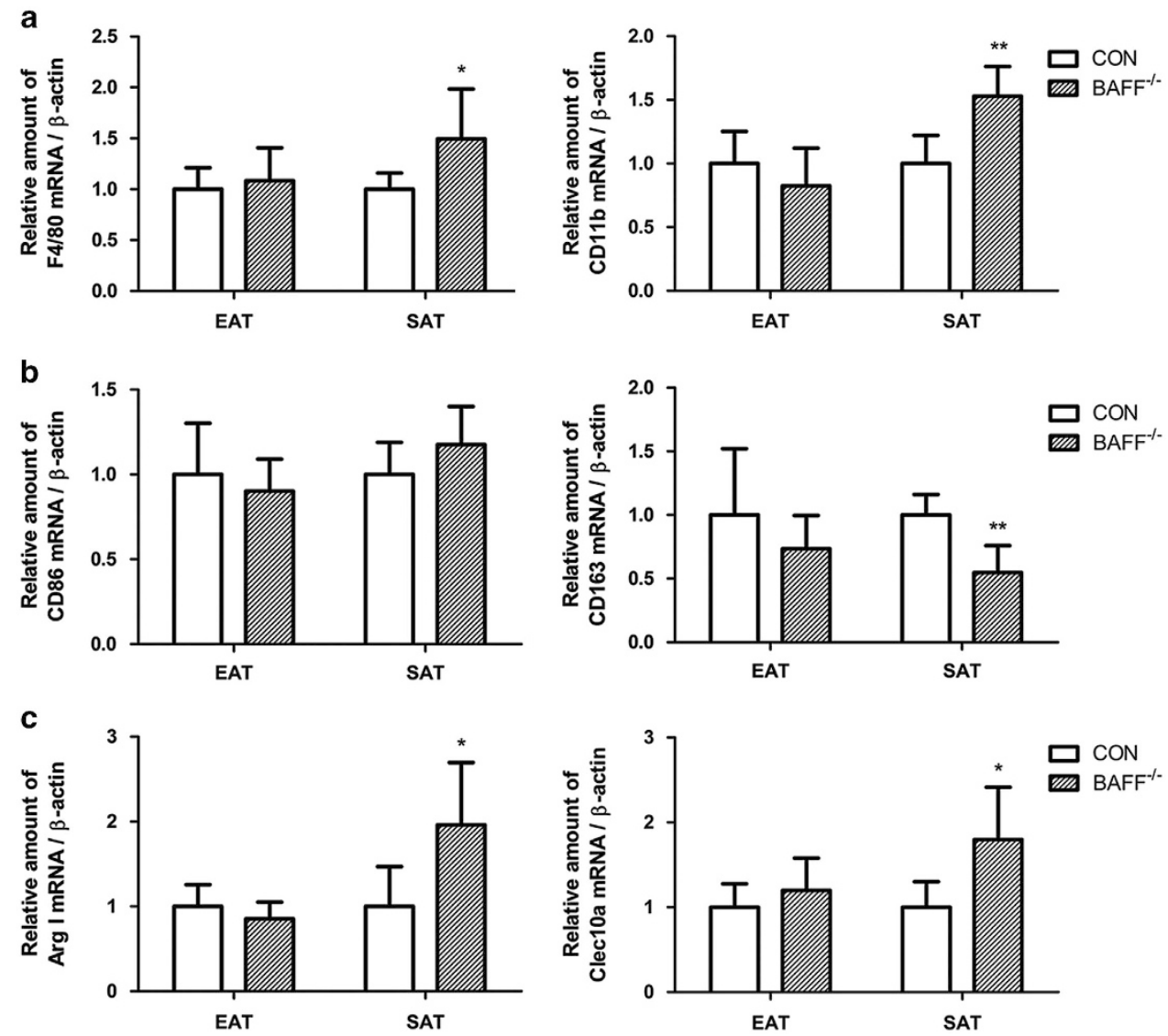

Figure 5 Macrophage marker expression in fat tissue. (a) Analysis of F4/80 and CD11b. (b) CD86 and CD163. (c) Arg I (arginase-1) and Clec10a (C-type lectin domain family 10, member A) mRNA expression in epididymal adipose tissue (EAT) and subcutaneous adipose tissue (SAT) from high-fat diet (HFD)-induced obese mice. mRNA analysis results are expressed relative to untreated control cells and is represented as the mean \pm s.e. Experiments were conducted two times. Mean values with letters are significantly different $\left({ }^{*} P<0.05\right.$ and ${ }^{* *} P<0.01$ ) by Student's $t$-test. BAFF, B-cell-activating factor; CON, control.

However, ATCM from $\mathrm{BAFF}^{-1-}$ SAT increased the expression of those genes (Figure 4a). The mRNA expression of inflammatory cytokines (IL-6, COX-2, haptoglobin and leptin) were decreased in adipocytes treated with ATCM from the EAT of $\mathrm{BAFF}^{-1-}$ mice. In contrast, there were no significant changes in the expression of these cytokines in ATCM from the SAT of $\mathrm{BAFF}^{-/-}$mice (Figure 4b).

\section{M2 macrophage infiltration was determined in SAT}

Given that adipose tissue expansion is known to be related to macrophage infiltration, we determined macrophage markers at the mRNA level. F4/80 and CD11b were examined as macrophage infiltration markers and results showed expression of those genes were unchanged in the EAT but upregulated in the SAT of $\mathrm{BAFF}^{-1-}$ mice (Figure 5a). Levels of inflammationpromoting M1 macrophages were determined by the expression of CD86 and CD163. The expression of CD86 did not show any changes, but CD163 was significantly downregulated in SAT in the absence of BAFF (Figure 5b). We next examined the M2 macrophage markers arginase-1 and Clec10a (C-type lectin domain family 10 , member $\mathrm{A}$ ) and found that the expression of those genes was significantly upregulated in the
SAT of $\mathrm{BAFF}^{-1-}$ mice, whereas no changes were observed in EAT (Figure 5c).

\section{DISCUSSION}

In this study, we have shown that BAFF knockout promotes lipogenesis in a depot-specific manner and reduces the production of inflammatory molecules in obese mice. When $\mathrm{BAFF}^{-1-}$ mice were fed with an HFD, SAT mass was selectively increased while EAT mass decreased. In the SAT, there was a downregulation of inflammatory gene expression, although fat mass increased. This was followed by a reduction in the overall concentration of circulating cytokines, which suggests an improvement in systemic inflammation when BAFF is absent in obesity.

To examine whether the absence of BAFF could lead to dietinduced obesity, we fed 6-week-old $\mathrm{BAFF}^{-/-}$and control mice with a standard chow diet or an HFD for 10 weeks and monitored their weight gain. Our data showed that the body weight of $\mathrm{BAFF}^{-/-}$mice was significantly increased after 6 weeks of feeding with HFD. However, the $\mathrm{BAFF}^{-1-}$ mice fed the standard chow diet did not show a remarkable difference in weight gain compared with their controls (data 
not shown). We then measured the weight of each adipose depot and found that the weight of the SAT increased, whereas that of the EAT decreased in $\mathrm{BAFF}^{-/-}$mice. However, the mass of visceral adipose tissue was similar between the two groups.

To know whether these changes were due to modulation of either lipogenesis and/or lipolysis, we measured mRNA expression of genes involved in these pathways. Lipogenic enzymes (FAS and acetyl-CoA carboxylase) were shown to be upregulated in SAT and downregulated in EAT. The lipolysis regulatory genes carnitine palmitoyl acyltransferase-1 and adiponectin $^{33}$ were decreased in SAT and increased in EAT. Therefore, increased lipogenesis and decreased lipolysis together resulted in the SAT mass increase. Not surprisingly, because visceral adipose tissue fat mass was not altered, there was also no change in the lipogenic gene expression of $\mathrm{BAFF}^{-1-}$ mice compared with the control mice (data not shown); hence, the studies focused on the SAT and EAT.

The effects of BAFF knockout in mice were further confirmed in murine 3T3-L1 adipocytes. We treated cells with recombinant BAFF and neutralizing BAFF-R antibody to mimic a BAFF knockout. The results showed that the treatment of BAFF inhibits lipogenesis, while cotreatment with BAFF-R antibody neutralized the effects of BAFF. This suggests that the in vitro method recapitulates the effects of BAFF knockout in the setting of obesity, especially in SAT.

We observed smaller and greater numbers of adipocytes in the SAT of $\mathrm{BAFF}^{-1-}$ mice by hematoxylin and eosin staining. This result suggests that induction of adipogenesis is another arm that contributed to the SAT mass increase. To identify this, we measured PPAR $\gamma$ expression, but there was no significant difference between the two groups (data not shown). It is possible that the window in which PPAR $\gamma$ is increased occurred earlier than the 10-week time point when the experiment was completed. Investigations into the temporal profile of PPAR $\gamma$ during high-fat feeding would improve our understanding of adipogenesis in obese $\mathrm{BAFF}^{-1-}$ mice. Using our in vitro assay, we have also demonstrated that the addition of BAFF inhibited the expression of the adipogenic transcription factors PPAR $\gamma$ and SREBP1c and that the neutralizing BAFF-R antibody treatment deactivated the inhibitory mechanism of adipogenesis. Therefore, BAFF knockout may promote adipogenesis.

Although the effects of BAFF knockout were largely confirmed in vitro, the changes in their gene expression appeared marginal. This result is most likely due to the concentration of BAFF used. Previous studies have reported an increase in inflammation when 3T3-L1 adipocytes were treated with $200 \mathrm{ng} \mathrm{ml}^{-1}$ of BAFF. However, the concentration of BAFF detected in mouse serum is $5-15 \mathrm{ng} \mathrm{ml}^{-1}$. 34,35 Therefore, the concentration of BAFF used in this study $\left(10 \mathrm{ng} \mathrm{ml}^{-1}\right)$ more closely reflects physiological levels.

It has been reported that SAT has beneficial effects on whole body metabolism in a mouse transplantation model. ${ }^{36}$ By transplanting adipose tissue to the subcutaneous region, an increase in SAT mass improved obesity-related complications. Given that $\mathrm{BAFF}^{-1-}$ mice show a selective increase in SAT mass, we hypothesized that this may be advantageous by reducing inflammation in obesity. Thus, we examined mRNA expression of inflammatory cytokines in SAT and EAT. In the SAT MCP-1, haptoglobin and leptin expression were not changed, while IL-6 and COX-2 expression increased. In the EAT, all the genes examined were downregulated in the absence of BAFF owing to the decrease in fat mass. ${ }^{37}$ More importantly, overall levels of cytokines in the circulation were reduced in $\mathrm{BAFF}^{-1-}$ mice. This suggests that the decrease in EAT mass drove the amelioration of systemic inflammation in obese mice. In addition, we showed that SAT expansion is accompanied by macrophage infiltration, especially M2 macrophages. Altogether, our data suggest that increased SAT mass in $\mathrm{BAFF}^{-1-}$ mice would have beneficial effects on metabolism. Further studies should characterize the metabolic phenotypes of $\mathrm{BAFF}^{-1-}$ mice such as insulin sensitivity and hepatic steatosis.

Finally, we showed that the molecules secreted from SAT and EAT of obese $\mathrm{BAFF}^{-1-}$ mice generated different effects. When 3T3-L1 adipocytes were cultured with EAT ATCM from $\mathrm{BAFF}^{-1-}$ mice fed an HFD, genes involved in lipogenesis and inflammation were all downregulated. Although SAT ATCM did not modulate lipogenesis or inflammation as we found in the mouse model, adipose tissue is an endocrine organ, and its secreted molecules exert autocrine/paracrine activities. Therefore, investigating the secretome profiles of EAT and SAT, or alternatively, using a microarray targeted to metabolism, would increase our understanding of how BAFF knockout differentially affects each adipose depot.

For the first time, we have demonstrated the function of BAFF in obesity using BAFF knockout mice. Thus far, research has been limited to BAFF-R knockout mice. However, this produces a discrepancy in the development of obesity-related complications for BAFF-R knockout mice compared with control animals. For example, BAFF- $\mathrm{R}^{-1-}$ mice developed insulin resistance, while hepatic steatosis was improved. ${ }^{32}$ Because BAFF transduces signaling through three different receptors, some compensatory mechanisms may be present in BAFF-R knockout mice. Thus, further studies on obesityrelated complications in BAFF knockout mice would elucidate a mechanistic function of BAFF in obesity.

In this report, we demonstrated that BAFF knockout improves systemic inflammation in obesity via the redistribution of adipose tissue into subcutaneous areas. This finding largely supports previous reports from our group that suggest that BAFF acts as a novel adipokine that regulates inflammation. ${ }^{25}$ Moreover, this work provides a platform for the development of therapeutic interventions such as antagonizing BAFF activity to combat obesity-related metabolic disease.

\section{ACKNOWLEDGEMENTS}

This research was supported by the National Research Foundation of Korea (KRF-2010-0009677) and No. 20130086 of Handong Global University Research Grants. We thank Dr Yu-Hee Kim and Julie 
Webster for conversations on these issues and helpful feedback on this document.

1 Calle EE, Kaaks R. Overweight, obesity and cancer: epidemiological evidence and proposed mechanisms. Nat Rev Cancer 2004; 4: 579-591.

2 Dandona P, Aljada A, Chaudhuri A, Mohanty P, Garg R. Metabolic syndrome: a comprehensive perspective based on interactions between obesity, diabetes, and inflammation. Circulation 2005; 111: 1448-1454.

3 Grundy SM. Obesity, metabolic syndrome, and cardiovascular disease. J Clin Endocrinol Metab 2004; 89: 2595-2600.

4 Fantuzzi G. Adipose tissue, adipokines, and inflammation. J Allergy Clin Immunol 2005; 115: 911-919.

5 Wisse BE. The inflammatory syndrome: the role of adipose tissue cytokines in metabolic disorders linked to obesity. J Am Soc Nephrol 2004; 15: 2792-2800.

6 Trayhurn P, Wood IS. Adipokines: inflammation and the pleiotropic role of white adipose tissue. Br J Nutr 2004; 92: 347-355.

7 Matarese G, Moschos S, Mantzoros CS. Leptin in Immunology. J Immunol 2005; 174: 3137-3142.

8 Stofkova A. Leptin and adiponectin: from energy and metabolic dysbalance to inflammation and autoimmunity. Endocr Regul 2009; 43: 157-168.

9 Muredach PR, Michael L, Megan LW, Anand R, Mitchell AL, Daniel JR. Resistin is an inflammatory marker of atherosclerosis in humans. Circulation 2005; 111: 932-939.

10 Stefan L, Sonja H, Daniela L, Susanne F, Stefan M, Franz-Georg H et al. Identification and validation of novel adipokines released from primary human adipocytes. Mol Cell Proteom 2012; 11: 01504-01513.

11 Tan BK, Adya R, Farhatullah S, Lewandowski KC, O'Hare P, Lehnert H et al. Omentin-1, a Novel Adipokine, is Decreased in Overweight InsulinResistant Women with Polycystic Ovary Syndrome: Ex Vivo and In Vivo Regulation of Omentin-1 by Insulin and Glucose. Diabetes 2008; 57: 801-808.

$12 \mathrm{Kim}$ YH, Choi BH, Cheon HG, Do MS. B cell activation factor (BAFF) is a novel adipokine that links obesity and inflammation. Exp Mol Med 2009; 41: 208-216.

13 Lamers D, Famulla S, Wronkowitz N, Hartwig S, Lehr S, Ouwens DM et al. Dipeptidyl Peptidase 4 Is a Novel Adipokine Potentially Linking Obesity to the Metabolic Syndrome. Diabetes 2011; 60: 1917-1925.

14 Paul AM, Ornella B, Amy O, Krystyna P, David WL, Ping F et al. BLyS: Member of the Tumor Necrosis Factor Family and B Lymphocyte Stimulator. Science 1999; 285: 260-263.

15 Pascal S, Fabienne M, Véronique S, Kay H, Jean-Luc B, Nils H et al. BAFF, a Novel Ligand of the Tumor Necrosis Factor Family, Stimulates B Cell Growth. JEM 1999; 189: 1747-1756.

16 Craxton A, Magaletti D, Ryan EJ, Clark EA. Macrophage- and dendritic cell99).endent regulation of human B-cell proliferation requires the TNF family ligand BAFF. Blood 2003; 101: 4464-4471.

17 Bernardetta N, Ornella B, Viktor R, Paul AM, Henrik So, Thi SM et al. Synthesis and release of B-lymphocyte stimulator from myeloid cells. Blood 2001; 97: 198-204.

18 Michael K, Teresa GC, Fang Q, Ann BS, Colleen M, Kathy S et al. Crystal structure of extracellular human BAFF, a TNF family member that stimulates B lymphocytes. J Mol Biol 2002; 315: 1145-1154.

19 Vassilia-Ismini A, George N, Vassiliki P, Marilena K, Maria V, Panayiotis T et al. Adipocytes as Immune Cells: Differential Expression of TWEAK, BAFF, and APRIL and Their Receptors (Fn14, BAFF-R, TACl, and BCMA) at Different Stages of Normal and Pathological Adipose Tissue Development. J Immunol 2009; 183: 5948-5956.

20 Gras MP, Laâbi Y, Linares-Cruz G, Blondel MO, Rigaut JP, Brouet JC et al. BCMAp: an integral membrane protein in the Golgi apparatus of human mature B lymphocytes. Int Immunol. 1995; 7: 1093-1106.

21 Mackay F, Schneider P. Cracking the BAFF code. Nat Rev Immunol 2009; 9: 491-502.
22 Do MS, Jeong HS, Choi BH, Hunter L, Langley S, Pazmany L et al. Inflammatory gene expression patterns revealed by DNA microarray analysis in TNF- $\alpha$-treated SGBS human adipocytes. Yonsei Med J 2006; 47: 729-736.

23 Wabitsch M, Brenner RE, Melzner I, Braun M, Möller P, Heinze E et al. Characterization of a human preadipocyte cell strain with high capacity for adipose differentiation. Int J Obes Relat Metab Disord 2001; 25: 8-15.

24 Fischer-Posovszky P, Newell FS, Wabitsch M, Tornqvist HE. Human SGBS cells-a unique tool for studies of human fat cell biology. Obes Facts 2008; 1: 184-189.

$25 \mathrm{Kim}$ MY, Kim DH, Do MS. B-cell-activating factor is a regulator of adipokines and a possible mediator between adipocytes and macrophages. Exp Mol Med 2013; 45: e4.

26 Hajer GR, van Haeften TW, Visseren FL. Adipose tissue dysfunction in obesity, diabetes, and vascular diseases. Eur Heart J 2008; 29: 2959-2971.

27 Mackay F, Woodcock SA, Lawton P, Ambrose C, Baetscher M, Schneider P et al. Mice transgenic for Baff develop lymphocytic disorders along with autoimmune manifestations. J Exp Med 1999; 190: 1697-1710.

28 Sage AP, Tsiantoulas D, Baker L, Harrison J, Masters L, Murphy D et al. BAFF receptor deficiency reduces the development of atherosclerosis in mice. Arterioscler Thromb Vasc Biol 2012; 32: 1573-1576.

29 Kyaw T, Cui P, Tay C, Kanellakis P, Hosseini H, Liu E et al. BAFF receptor $\mathrm{mAb}$ treatment ameliorates development and progression of atherosclerosis in hyperlipidemic ApoE(-/-) mice. PLoS One 2013; 8: e60430.

30 Hamada M, Abe M, Miyake T, Kawasaki K, Tada F, Furukawa S et al. B cell-activating factor controls the production of adipokines and induces insulin resistance. Obesity 2011; 19: 1915-1922.

31 Tada F, Abe M, Kawasaki K, Miyake T, Shiyi C, Hiasa Y et al. B cell activating factor in obesity is regulated by oxidative stress in adipocytes. J Clin Biochem Nutr 2013; 52: 120-127.

32 Kawasaki K, Abe M, Tada F, Tokumoto Y, Chen S, Miyake T et al. Blockade of B-cell-activating factor signaling enhances hepatic steatosis induced by a high-fat diet and improves insulin sensitivity. Lab Invest 2013; 93: 311-321.

33 Liping Q, Brice K, Jerome S, Jianhua S. Adiponectin inhibits lipolysis in mouse adipocytes. Diabetes 2011; 60: 1519-1527.

34 Patrizia S, Yongmei H, Ching-Liang C, Thi-Sau M, Anthony LD, Marco AC et al. Myeloid cells, BAFF, and IFN- $\gamma$ establish an inflammatory loop that exacerbates autoimmunity in Lyn-deficient mice. J Exp Med 2010; 207: 1757-1773

35 Yan Z, Stefania G, John PG, Jane AG, Marc M. A role for B cell-activating factor of the TNF family in chemically induced autoimmunity. J Immunol 2005; 175: 6163-6168.

36 Tran TT, Yamamoto Y, Gesta S, Kahn CR. Beneficial effects of subcutaneous fat transplantation on metabolism. Cell Metab 2008; 7: 410-420.

37 Samantha LH, Lindsay EW, Michael G, Donald JC, David EJ. Intrinsic depot-specific differences in the secretome of adipose tissue, preadipocytes, and adipose tissuedipose tissue, and adipose tissue. Diabetes 2010; 59: 3008-3016.

38 Mackay F, Pascal S. Cracking the BAFF code. Nat Rev Immunol 2009; 9 : 491-502.

(1) (2) This work is licensed under a Creative Commons Attribution-NonCommercial-ShareAlike 3.0 Unported License. The images or other third party material in this article are included in the article's Creative Commons license, unless indicated otherwise in the credit line; if the material is not included under the Creative Commons license, users will need to obtain permission from the license holder to reproduce the material. To view a copy of this license, visit http:// creativecommons.org/licenses/by-nc-sa/3.0/ 